\title{
Analysis and Strategies of the Common Tunnel Problems
}

\author{
S.P. Huang, M.L. Guo \\ Guangdong University of Science \& Technology \\ Guangdong, China
}

\begin{abstract}
The tunnel construction has made considerable progress in our country for years, resulting in tunnel problems. A survey revealed that the common tunnel problems in our country mainly include lining erosion, water damage, basement sink, and mud-pumping etc. These problems seriously affects the tunnel's normal passage and transport safety. To deeply analysis the types and causes of these common problems, and targeted formulate countermeasures to treat these problems, will have a positive guidance for the tunnel construction.
\end{abstract}

Keywords-tunnel; problems; causes; countermeasures

\section{INTRODUCTION}

As our national economy grows rapidly, Chinese tunnel construction is entering a fast-development era. "By the end of 2010, 7384 highway tunnels had ramified all over the country, with a length of 5122.6 kilometers, among which extra-long tunnels are 265, with a length of 1138 kilometers, long tunnels 1218, with a length of 2020.8 kilometers. With the successive completion of Zhongnanshan highway tunnel in Qinling (18.02 kilometers in length, ranking first in the world by scale, second by length), Chongming tunnel-bridge in Shanghai, Xiang'an undersea tunnel in Xiamen, China has become a country with the most highway tunnels in the world, and also rates first in railway tunnels both by number and length according to statistics."[1] However, statistics suggest that almost $60 \%$ of the railway and highway tunnels suffer from such problems as lining erosion, water damage, basement sink, and mudpumping etc. to varying degrees, which severely affects transportation safety and results in huge losses in manpower, material resources and financial resources. To reduce the tunnel problems, it is necessary to carry out an in-depth analysis of the classification and causes of the common tunnel problems, and then put forward countermeasures accordingly.

\section{ClassificATION OF COMMON TUNNEL PROBLEMS}

\section{A. Different Types of Tunnel Lining Erosion}

Mainly two parts of a tunnel are prone to tunnel lining erosion. One is metal components set up near tunnel surrounding rock which are corroded by humid environment. The other is concrete walls near tunnel lining which have honeycombs, pitting surface, aggregate segregation, peeling plaster, deformation and fracture because of the groundwater seepage. Therefore, according to the different causes, tunnel lining erosion can fall into the categories of water erosion, smoke erosion, aggregate swelling and frost erosion.

1) Water erosion: Water erosion refers to corrosion damage of tunnel arch, tunnel side wall, tunnel invert, drainage ditch etc. caused by groundwater seepage. Water erosion of tunnel lining can also be divided into the following three types, eg. water decomposition, erosion of sulfate, and erosion of magnesium salt and carbide.

2) Smoke erosion: Smoke erosion refers to corrosion damage of surrounding-rock concrete. When the steam locomotive tractor runs though the tunnel, it produces hightemperature smoke which may toast and corrode the concrete, causing damage. Products contained in the smoke can resolve the internal components of concrete, which is called chemical smoke erosion. High-temperature smoke can directly toast the concrete, which is mechanical erosion.

3) Aggregate swelling: When the aggregates in the tunnel lining concrete are not up to standard, they are prone to dissolving and swelling in water, causing small holes in the concrete or expansion fracture of the lining, which severely endangers its stability and service life in turn.

4) Frost erosion: Frost erosion mainly happens in high cold areas. One fifth of our land area is covered by permafrost, where railway and highway tunnels suffer from freezing and thawing. Tunnel lining can easily crack during freezing period and collapse during thawing period. Arch of the surrounding rock and side walls can be prone to deformation. All the damage will severely lower the stability and safety of the tunnel lining.

\section{B. Different Types of Tunnel Bed Problems}

"Tunnel bed problems refer that after a long-period operating of railway tunnels, the base structure of tunnels may crack, wear out, sink, froth and pump mud etc.”[2] According to statistics, "The Railway Administration of Zhengzhou governs 1152 tunnels, only 25\% of which are up to standard. Problems of frothing and mud-pumping which can directly affect the operating of railway account for $20 \%$ substandard tunnels. In some sections, the tunnel bed disease rate can top $50 \%$. For example, in the Xiangfan-Chongqing line liuliping section, 34 of 76 tunnels suffer from problems of frothing and mud-pumping."[3] We can see that tunnel bed disease is a common tunnel disease with a higher proportion than other problems in our country, which greatly endangers the transportation safety.

1) Tunnel bed cracking : Under tunnel construction, impacted by construction materials and techniques, the tunnel bed may fail to achieve seamless joint with the bed rock, 
leaving gaps which groundwater may leak in. Besides, the constant vibrations of trains can easily causes cracking of the tunnel bed.

2) Tunnel bed sinking: Corrosive water leaking in the tunnel bed may soften and sink the base structure of the tunnel after soaking the concrete for a long time. If the tunnel bed is backfilled loosely and produces holes in the stratum, the tunnel bed may also collapse with outside disturbance.

3) Frothing and mud-pumping: If water resistance is not taken into consideration in designing the tunnel construction, groundwater can leak in the tunnel bed and erode the concrete, causing small holes and cracks. With the constant vibrations of trains acting on it, the bending stress on the tunnel bed may disorder and aggravate the cracking, fragment and even pulverize the tunnel bed concrete in the end, resulting in the problems of frothing and mud-pumping.

\section{Different Types of Water Damage}

"Tunnel damage by water refers to disturbance and harm causesd by water in the construction and operating process."[4] Statistics show that most of railway and highway tunnels in our country suffer damage by water, which highly endangers the stability of the tunnel structure and easily trigger other tunnel problems such as tunnel lining disease. Water damage is a commonly seen and harmful one among tunnel problems.

1) Water damage in the course of tunnel construction: Here it refers to damage causesd by the leakage of the groundwater reserved in the surrounding rock and surface water near the tunnel in the tunnel rock. This kind of damage may harm the physical and mental health of the constructors, and lead to erosion of construction equipment which can imperil personal safety; if surface water floods into the tunnel, it may easily bring about collapse, submerge the construction equipment, endanger lives of the constructors and result in significant economic losses.

2) Water damage in the tunnel operating process: After putting into operation, tunnels are still apt to suffer the following two kinds of water damage. One is water leakage or inflow, the other one is surface ponding near the tunnel lining.

3) Underflow dissolution : Underflow dissolution refers to damage causesd by long-term seepage of groundwater reserved in the surrounding rock, resulting in dissolution of tunnel lining. If tunnel bed suffers severe underflow dissolution, it may sink, deform, crack and even collapse.

\section{COMmon CAUSES OF TUNNEL PROBLEMS}

\section{A. Causes of Tunnel Lining Erosion}

Tunnel lining is mainly corroded becauses of the groundwater environment, including the following reasons such as erosion by groundwater leakage, erosion by freezing and thawing and unqualified construction quality and operation.

\section{B. Causes of Tunnel Bed Disease}

Tunnel bed disease is causesd by various reasons, such as poorly-designed tunnel bed structure, unreasonable drainage facility setting in the tunnel, constant vibrations of trains and groundwater seepage and so on, among which groundwater seepage is the most significant one.

\section{Causes of Water Damage}

The groundwater system maintains balance before the commencement of the tunnel construction, but the excavation work breaks the balance, causing the convergence of groundwater from all directions in the tunnel.[5] That is how the damage forms. The tunnel damage by water is closely related to the following three man-made causes such as poor drainage system, unqualified construction quality, backward supervision and acceptance.

\section{Prevention And Control Measures of the COMMON TUNNEL PROBLEMS}

\section{A. Prevention and Control Measures for Lining Erosion}

1) Stabilize the rock mass by controlling the groundwater: The typical form of lining erosion is that groundwater seeps in the rock mass and erodes the wall rock concrete which had soaked into the groundwater for a long time, thereby weakening the strength of the rock. To prevent the lining erosion, tunnel drainage system must be designed in a scientific way so that the groundwater gathered around the tunnel can be discharged. Laying viscid waterproof layer on both sides of the rock lining can also soak up groundwater which seeped in the lining and keep the rock lining dry.

2) Stabilize the rock mass by injecting cement grout: If the drainage system and water-proof system are not installed in the lining of the tunnel, cement grout can be injected into it. This process not only enhances the stability of the wall rock, but also prevents groundwater from seeping into artificial consolidation area of the wall rock, fundamentally reducing the erosion of tunnel lining causesd by groundwater, smog and frost.

3) Replace or reinforce the lining: Some linings are badly eroded by water, smog and frost. Problems like cracks, deformation and displacement appear. As for those linings, they can be reinforced or replaced by grouting, patching, spraying concrete, strengthening arch or substituting the structure to ensure the safety of the tunnel.

4) Strengthen the lining maintenance: To prevent and control the lining erosion, tunnel management organizations should reinforce tunnel prospecting, measuring and evaluating. Meanwhile tunnel designers should improve the design grade of tunnel concrete to increase the impermeability of lining concrete and its capacity of resisting water erosion, smog erosion and frost erosion.

\section{B. Prevention and Control Measures for Tunnel Basement Problems}

1) Groundwater drainage: The major causes of tunnel 
basement problems is the groundwater erosion. Therefore, the key to prevent and control basement problems is to discharge the groundwater and lower the groundwater table, keeping the bedrock dry as well as stopping the erosion. One way to weaken the erosion power of groundwater is to design proper drainage ditch and make full use of it. Both horizontal and longitudinal blind ditches can be built to help discharging the groundwater and ensuring the quality of the basement.

2) Weaken the influence of train vibrations: Inserting viscid waterproof layer between tunnel basement structure and the bedrock in constructing the basement not only prevents the groundwater from seeping, but also weakens the vibration induced by running trains. Besides, deepening the roadbed properly also weakens the influence of train vibration.

3) Improve the bearing capacity of the tunnel bed: Tunnel bed withstands both the pressure of wall rock and the pressure induced by repeated loaded train vibration, and can be damaged easily and have cracks on it. For this reason, the intensity, water density and crack-resistance of the tunnel bed concrete should all be taken into consideration in designing the structure of the tunnel bed, including using double steel reinforcement layout in water-rich zone, strengthening concrete vibrators during the tunnel bed perfusion and clearing off the virtual ballast completely to improve the watertight performance and crack-resistance capacity of the tunnel bed.

4) Strengthen the tunnel bed maintenance: When the tunnel is put into service, the maintenance of the tunnel bed should be enhanced by cleaning the basement track and unblocking the side ditch. In this way, the tunnel bed is dry and in a good condition, which reduces the occurrence of the tunnel problems.

\section{Prevention and Control Measures for Water Damage}

Water damage is one of the commonest and most serious tunnel problems. The control of the water damage should adhere to local conditions and combine draining, blocking and cutting together. The specific methods are as follows.

1) Discharge the groundwater and surface water: For those tunnels in water-rich area, drainage ditch should be laid on both side of the tunnel. A certain amount of underground pipes and wells should also be added to deepen the ditches. Extending the side ditches under the rail surface for 1.5 meters can prevent water from leaking into the lining effectively, helping the basement discharging stagnant water and keeping the roadbed and lining dry. As for the long and large tunnel, parallel pilot tunnel should be added to help discharging excessive groundwater and surface water. Cold proofing drain cavern can be built under the maximum frost line in cold regions to discharge fissure water seeped into the wall rock. Surface water seeping into the tunnel can causes damages, too. In this respect, discharging and siphoning off surface water by filling pits, ditching and laying smooth drainage system are the necessary measures to prevent and control water damage.
2) Grout to block the water: Grouting materials with good groutability, high solidity, and strong impermeability should be selected and used. Then cement grout or GRM cement grout is injected into lining, backfill layer and basement where water seepage appears frequently to increase wall rock's impermeability and its capacity to resist pressure, thus preventing the groundwater from seeping.

3) Make use of both internal and external waterproof layers: For tunnels severely damaged by water, not only an external waterproof layer made from waterproof concrete is built, but also an internal waterproof layer is laid to stop the seepage.[6] The internal waterproof layer can coat with rubber asphalt, tar polyurethane and water-proofing additive, etc. or press and scrape with $\mathrm{R}$ material blended with acrylic polymer emulsion and other materials, or spray with cement grout, cation emulsified asphalt and so on. The selection of the three measures above should depending on different situations becauses each of them has strengths and weaknesses. Combining both internal and external waterproof layers in water control, the harm to tunnel is reduced.

\section{CONCLUSION}

Due to that areas where tunnels run through always have complex geological conditions such as fractured rocks, delicate surrounding rocks, metamorphic rock belts and fault fracture zone, adding the complex hydrological conditions, the tunnels are prone to suffer from common tunnel problems like tunnel lining erosion, damage by water and tunnel bed sinking frothing and mud-pumping and so on, which severely affects transportation safety and results in huge losses in manpower, material resources and financial resources. Therefore, a feasible countermeasure is to carry out a comprehensive approach from the perspective of investigation, design, construction and supervision etc. based on an in-depth analysis of the classification and causes of the common tunnel problems.

\section{REFERENCE}

[1] A Development Research Report on Highway Tunnel Engineering. (2001) CHTC Tunnel Engineering Branch[R]. http://www.docin.com/p597271551. html, 2012-4.

[2] C.H. Shi, L.M. Peng \& J. Huang. Generation Mechanism and Treatment Measures of Railway Tunnel Bed problems[J]. China Railway Science, vol.4, pp:62-66, 2005.

[3] W.T. Zhu, L.Q Li. Current Situation and causes Analysis of Tunnel Bed problems[J]. Modern Tunneling Technology, vol.5, pp:42-44, 2001.

[4] Y.X. Zhang. Analysis on the Hazards and causes of the Common Deteriorations in Tunnel Engineering[J]. The World of Buiding Materials, vol.1, pp:69-72, 2008.

[5] D.Y. Wan. Treatment Measures of Water Damage in Operating Railway Tunnel[J]. Railway Engineering, vol.12, pp:13-15, 2000.

[6] Z.W. Bao. On Tunnel Lining problems and Its Prevention and Treatment[J]. China Science and Technology Information, vol.3, pp:54, 2012. 